\title{
A letter of thanks to the founding editors of Sleep and Breathing
}

\author{
Arn H. Eliasson ${ }^{1}$ - Thomas Penzel $^{2}$ - Fernanda Almeida ${ }^{3}$
}

Published online: 21 February 2017

(C) Springer-Verlag Berlin Heidelberg 2017

The Journal Sleep and Breathing owes an enormous debt of gratitude to the two co-founders and co-editors-in-chief, Nikolaus Netzer, MD PhD, and Kingman Strohl MD, who are ceding their roles this year to new editors-in-chief. A brief tribute and thank you to these inventive and industrious men follows.

The idea for Sleep and Breathing germinated from the development of an informative handout for patients in a sleep clinic in Hagen, Germany. This effort brought attention to the larger need for a forum to disseminate emerging research on sleep in general and sleep apnea in particular. Initially, published sleep research in Europe focused on basic physiology but it became clear that a scientific journal for clinical sleep medicine was urgently needed. For example, clinical research presented in 1984 by Dr. Meyer Ewert, who invented and studied the first oral appliance, was not taken seriously due to the lack of a venue to provide peer review and publication of his ground-breaking work.

To address the need for a clinical journal of sleep medicine, the quarterly journal Atmung und Schlaf was published in German in 1994 and 1995 by Dr. Hans-Christian Blum. In the spring of 1996, Dr. Netzer transformed the journal into Sleep and Breathing with articles rendered side-by-side in

Arn H. Eliasson

aheliasson@aol.com

1 Department of Medicine, Uniformed Services University of the Health Sciences, 4301 Jones Bridge Road, Bethesda, MD 20814-4799, USA

2 Sleep Medicine Center, Charite Universitätsmedizin Berlin, Chariteplatz 1, 10117 Berlin, Germany

3 Faculty of Dentistry, University of British Columbia, Vancouver, BC, Canada
German and English. Dr. Netzer's accomplished father, Norbert Netzer, served as the bidirectional translator for these early volumes. The tradition was established to grace the cover of each printed journal with art depicting a subject at sleep. Early articles were written by Drs. William Dement, Kingman Strohl, and Rudolpho Alvarez Sala.

Late in the year 1996, Dr. Nikolaus Netzer was awarded a visiting professorship at the Veterans Affairs Medical Center in Cleveland, Ohio, cementing a working relationship between Dr. Netzer and Dr. Kingman Strohl, a tenured professor of medicine, oncology, physiology, and biophysics at Case Western Reserve University in Cleveland. While nurturing the nascent journal Sleep and Breathing, Drs. Netzer and Strohl collaborated with other academics and practitioners to develop and validate a clinical tool to screen for sleep apnea, the Berlin Questionnaire, with outcomes published in the Annals of Internal Medicine in 1998.

From its inception, Sleep and Breathing was intended to encourage German sleep researchers to perform and publish high quality peer-reviewed studies and to help these researchers publish in English. The intention rapidly evolved for the journal to be welcoming of research efforts from the greater international community ranging from Europe to South Asia and East Asia with recent years including submissions from South America. Through its international outreach, the journal has succeeded magnificently with the number of high-quality international submissions growing annually. The journal's success has also been externally validated with its impact factor increasing from 0.22 to a high-water mark of 2.94.

A second legacy of Sleep and Breathing, dating from its earliest volumes, has been the strong connection with the dental sleep medicine community. As a result of the journal's encouragement of dental sleep research, it has served as the official journal of the Academies of Dental Sleep Medicine for Europe, Japan, Korea, and the Australasian Academy of 
Dental Sleep Medicine. Until 3 years ago, Sleep and Breathing was also the official journal of the American Academy of Dental Sleep Medicine.

Dr. Strohl observes that he and Dr. Netzer purposefully sought articles that were "edgy," that is, odd papers that were scientifically sound but which broke new ground or proposed theories out of the generally accepted norm. By nurturing innovative ideas in this fashion, advancements in sleep medicine could be encouraged in leaps forward and not just in step-wise gains.

As Drs. Netzer and Strohl are promoted to editors-in-chief emeriti, they express gratitude for the opportunity to grow the journal and to observe and be part of the publishing world. Drs. Netzer and Strohl also express their thanks to the many bright and industrious reviewers who have been willing to share their expertise and whose important work allows the journal to flourish. Readers of Sleep and Breathing can anticipate that the journal will continue to receive guidance from the founding editors. It is likely that occasional commentaries on timely subjects will be penned by these senior academics of sleep medicine. The journal Sleep and Breathing and the sleep medicine community at large owe a debt of gratitude to Dr. Nikolaus Netzer and Dr. Kingman Strohl for birthing and nurturing the journal to its current state of health and maturity. 